\title{
Cuidar e (não) vacinar no contexto de famílias de alta renda e escolaridade em São Paulo, SP, Brasil
}

\author{
Care and (non)-vaccination in the context of high-income \\ and well-schooled families in São Paulo \\ in the state of São Paulo, Brazil
}

Marcia Thereza Couto ${ }^{1}$
Carolina Luisa Alves Barbieri ${ }^{2}$

${ }^{1}$ Departamento de Medicina Preventiva, Faculdade de Medicina, Universidade de São Paulo (USP). Av. Dr. Arnaldo 455/2177, Cerqueira César. 01246903 São Paulo SP Brasil. marthet@usp.br

${ }^{2}$ Programa de PósGraduação em Medicina Preventiva, Faculdade de Medicina, USP.

\begin{abstract}
This paper analyzes the parental care dimension and the relationship with the decisions on (non)-vaccination of their children in the context of high-income and well-schooled families in São Paulo city/state. The research adopts the qualitative approach, using in-depth interviews conducted with 15 couples that were divided into three groups: vaccinators, selective vaccinators and non-vaccinators. The analytic-interpretative study of the data was performed by means of content analysis and in line with the benchmarks of care of health and family. For all the couples analyzed, the option of (non)-vaccination of their children is perceived as parental care and protection of the child. However, for the vaccinators, protection is to vaccinate their children; for the selective vaccinators, protection is to study case by case; and for the non-vaccinators, protection is not to vaccinate their children, but to protect them against the risks of vaccination. The study also revealed that the reasons for non-vaccination, selection and/or postponement of the vaccination schedule were similar to those found in the international literature. The study highlights the importance of socio-cultural comprehension of (non)-acceptance of vaccination in the context of parental care.
\end{abstract}

Key words Immunization, Child care, Qualitative research, Family
Resumo O trabalho analisa a dimensão do cuidado parental e suas relações com as decisões de (não) vacinar os filhos no contexto de famílias de alta renda e escolaridade de São Paulo, SP. A pesquisa se orienta pela abordagem qualitativa, com uso de entrevista em profundidade, realizada com 15 casais alocados em três grupos: vacinadores, vacinadores seletivos e não vacinadores. O percurso analítico-interpretativo dos dados foi realizado por meio da análise de conteúdo e segundo os referenciais de cuidado em saúde e família. Para todos os casais do estudo, a escolha da (não) vacinação dos filhos é concebida como um cuidado parental e proteção ao filho, porém, para os vacinadores, proteger é vacinar os filhos; para os vacinadores seletivos, proteger é singularizar cada caso; e para os não vacinadores, proteger é não vacinar os filhos, é proteger contra os riscos da vacinação. $O$ estudo revelou, também, que as justificativas da não vacinação e da seleção elou postergação do calendário vacinal foram semelhantes às encontradas na literatura internacional. O estudo aponta a importância da compreensão sociocultural da (não) aceitabilidade da vacinação no contexto do cuidado parental.

Palavras-chave Imunização, Cuidado infantil, Pesquisa qualitativa, Família 


\section{Introdução}

Na contemporaneidade, o cuidado em saúde infantil tem experimentado mudanças e permanências em decorrência de transformações no campo social, demográfico e médico. No tocante às transformações sociais e demográficas, merece destaque o incremento da escolarização feminina, o ingresso da mulher no mercado de trabalho, a valorização do igualitarismo nas relações entre o casal e a maior participação do homem no cuidado infantil; a queda na fecundidade e no tamanho das famílias e a ampliação da idade das mulheres para terem o primeiro filho ${ }^{1-3}$. Nos âmbitos das tecnologias médicas e das práticas de saúde, aspectos como o acelerado desenvolvimento técnico-científico em concepção e contracepção ${ }^{1}$, o aumento da precisão e rapidez dos diagnósticos e de intervenções terapêuticas'; ações advindas do campo da saúde pública como a melhoria na assistência pré-natal, o incentivo ao aleitamento materno e a efetividade do programa nacional de imunização infantil ${ }^{5}$, compõem um espectro de fatores necessários para que se possa compreender o lugar que o cuidado em saúde infantil assume nos dias atuais.

Considerando-se a relação vacinação e cuidado infantil, não se pode negar que como medida de prevenção em saúde pública, a vacinação é considerada uma intervenção de grande impacto na diminuição de morbimortalidade da população (superior à descoberta de antibióticos), perdendo somente para o saneamento básico e água potável ${ }^{6}$. Somado a isto, o contexto brasileiro apresenta especificidade por contar com o Programa Nacional de Imunização (PNI), criado em 1973, que se tornou uma das políticas públicas mais exitosas, por fornecer de forma universal e gratuita um extenso conjunto de vacinas à população infantil, pela produção e qualidade dos imunobiológicos distribuídos e pela equidade em termos de acesso às vacinas ${ }^{7,8}$. Diante deste quadro, sugere-se que no decorrer das últimas quatro décadas e com a consolidação do PNI no Brasil, assiste-se à emergência do que Hochman" chamou de "cultura de imunização" no Brasil contemporâneo e da vacina como um símbolo associado ao cuidado parental, que ultrapassa a perspectiva biomédica e da Saúde Pública, por atingir grande parte da população e penetrar de modo incisivo no universo familiar - como pode ser demonstrado pelo reconhecimento nacional desta política, sobretudo pela sua efetividade, extensão e expansão ${ }^{7,8}$. Tal proposição, entretanto, deve ser tomada em toda sua complexidade, especialmente quando se leva em consideração as particularidades do Brasil em termos de sua extensão territorial, características regionais e, da população brasileira, quanto a sua diversidade sociocultural e desigualdade socioeconômica.

Ao observamos mais detidamente para a cobertura vacinal no contexto brasileiro, vê-se variações segundo a região e o nível socioeconômico das famílias ${ }^{7}$. Em 2007, um estudo por inquérito domiciliar nacional evidenciou que crianças pertencentes às famílias de maior nível socioeconômico e escolaridade apresentaram as menores taxas de cobertura vacinal em 10 das 27 capitais do Brasil. Uma dessas foi a cidade de São Paulo que, apesar de atingir cobertura vacinal geral de $83,0 \%$, apresentou uma taxa de $71,2 \%$ no estrato A e $81,1 \%$ no estrato E, diferença estatisticamente significante ${ }^{9}$. Esta tendência - propensão inversa da taxa de vacinação e o nível socioeconômico e escolaridade - foi observada na cidade de São Paulo desde o início dos anos $2000^{10}$.

Assim, em contraponto aos avanços em saúde atribuídos à vacinação e sua legitimidade pela população mais ampla, alguns pais de alta renda e escolaridade em centros urbanos estão optando por não vacinarem seus filhos, problematizando esta intervenção como uma premissa do cuidado parental. Essas evidências sugerem uma mudança paradigmática no tocante à adesão à vacinação infantil: a transformação da esfera da acessibilidade aos serviços de saúde para o âmbito da aceitabilidade à vacina ${ }^{11}$.

No contexto internacional, estudos visando compreender as razões dos pais que não vacinaram seus filhos foram realizados ao longo das últimas duas décadas, em sua maioria, em países desenvolvidos (como Inglaterra, EUA, Canadá, Austrália), por meio de metodologia qualitativa e do depoimento das mães. Eles encontraram questões relacionadas à epidemiologia das doenças imunopreveníveis, ao mecanismo de ação e composição das vacinas, à seguridade e crítica à política pública e ao interesse financeiro ${ }^{12-15}$. No Brasil, as concepções dos pais sobre a imunização infantil e a compreensão da aceitabilidade da vacinação ainda são pouco conhecidas. Diante desse cenário, este trabalho tem o objetivo de compreender as dimensões do cuidado parental acerca da (não) vacinação infantil em famílias de alta renda e escolaridade residentes no Município de São Paulo-SP. A proposta deste artigo não se resume a descrever as razões da (não) vacinação no recorte social estudado, ou seja, os motivos de rejeição ou resistência à vaci- 
na, como é frequente na literatura científica sobre o tema; mas compreender como os pais significam o processo de (não) vacinar, que envolve a tomada de decisão e o manejo desta escolha, por entender que o feito de vacinar ou não os filhos permeia múltiplas facetas de ordem sociocultural $^{16}$. Nestes termos, a compreensão das concepções acerca da vacinação infantil será norteada pela perspectiva do cuidado parental, explorando o modo como uma intervenção biomédica - a vacinação infantil - dialoga e se traduz no interior da família, por meio do aspecto relacional da parentalidade e do cuidado em saúde da criança.

\section{Percurso metodológico}

Os dados empíricos que apoiam a discussão pretendida neste trabalho fazem parte de uma pesquisa mais ampla, financiada pelo Conselho Nacional de Desenvolvimento Científico e Tecnológico (CNPq), que investiga, desde a perspectiva de gênero e do cuidado, as representações de casais de alta renda e escolaridade de São Paulo-SP acerca do aleitamento, alimentação infantil e vacinação. O estudo foi conduzido após aprovação da Comissão de Ética em Pesquisa da Faculdade de Medicina da Universidade de São Paulo. A produção dos dados empíricos se norteou pela técnica de entrevista em profundidade, devido a sua potencialidade de captar, a partir de um roteiro flexível, os valores e os sentidos que os sujeitos atribuem a eventos de sua experiência pessoal ${ }^{17,18}$. As entrevistas foram realizadas no período de janeiro a julho de 2011 após esclarecimento, leitura, verificação da compreensão e assinatura do Termo de Consentimento Livre e Esclarecido pelos participantes. Para garantir o anonimato e a confidencialidade dos dados e dos sujeitos da pesquisa, utilizamos apenas as iniciais dos nomes dos entrevistados. No tocante à temática da vacinação, o roteiro das entrevistas visou encorajar os sujeitos a falarem sobre suas vivências na escolha ou não da vacinação infantil, as influências que permearam as tomadas de decisões e os sentimentos oriundos dessas vivências.

$\mathrm{Na}$ composição dos sujeitos da investigação, a opção no desenho metodológico foi o de privilegiar pais e mães casados, que moravam juntos e tinham pelo menos um filho com idade de até cinco anos (período em que se concentra a maior parte das indicações de vacinas na faixa etária infantil pelo PNI7). Os critérios de inclusão dos casais foram: (1) alta escolaridade, em que ambos tinham, no mínimo, nível superior comple- to; (2) pertencentes aos estratos de maior nível socioeconômico ${ }^{19} \mathrm{e}$ (3) residentes na área urbana de São Paulo. Os critérios de exclusão foram: (1) casais com filhos portadores de doenças crônicas ou perinatais; (2) casais separados ou que não coabitavam no mesmo domicílio.

A participação dos sujeitos na pesquisa foi orientada segundo a posição dos mesmos perante a vacinação infantil. Os casais foram divididos em três grupos: (1) vacinadores, os que imunizaram seus filhos conforme as recomendações do PNI; (2) vacinadores tardios ou seletivos, os que escolheram algumas vacinas e/ou postergaram suas datas e (3) não vacinadores, aqueles que não vacinaram seus filhos. A captação dos participantes foi feita por meio do procedimento de "bola de neve" 20 , estratégia apropriada para a identificação de populações minoritárias, excluídas ou de difícil acesso, como é o caso dos casais não vacinadores participantes do estudo. O número final de entrevistados não foi definido a priori e sim durante o trabalho de campo, usando o critério de saturação de falas e significados atribuídos à experiência no contexto da (não) vacinação dos filhos ${ }^{21}$. No total, participaram 15 casais, sendo 5 casais vacinadores, 5 casais vacinadores tardios ou seletivos e 5 casais não vacinadores.

As entrevistas foram realizadas com os membros dos casais de forma conjunta ou em separado, de acordo com a escolha e disponibilidade dos participantes. As entrevistas foram gravadas em áudio digital e tiveram duração média de 34,6 minutos cada. O conjunto das entrevistas totalizou um banco de dados em áudio de 971 minutos. Todas as entrevistas foram transcritas na íntegra e, na sequência, foi realizada a verificação da acurácia das transcrições.

A partir da leitura exaustiva do material produzido foram identificados os temas pré-definidos e os emergentes e feita a categorização de análise. No estágio inicial da análise foi utilizado o software NVivo versão 8, para auxiliar no agrupamento dos dados por categoria. Na sequência, o processo analítico-interpretativo do material empírico foi realizado por meio da análise de conteúdo temático ${ }^{18}$, cujo olhar aos depoimentos, ao contexto e à conexão destes com o momento histórico e sociocultural, se guiou pela antropologia interpretativa ${ }^{22}$. Os achados desse estudo foram cotejados aos da literatura científica concernente à vacinação e cuidado parental.

Os conteúdos que emergiram dos dados produzidos foram posteriormente interpretados segundo os referenciais de cuidado ${ }^{4,23} \mathrm{e}$ da família nas sociedades urbanas complexas ${ }^{24,25}$. 
O referencial de cuidado é orientado por perspectiva reflexiva e crítica que valoriza a dimensão relacional entre os sujeitos, num contexto de intersubjetividade. No âmbito das práticas de saúde, o cuidado faz uma aproximação dialógica entre os êxitos das tecnociências biomédicas com a sabedoria e o sucesso prático dos sujeitos envolvidos, cuja ponte se funda no que move e faz sentido aos indivíduos, às coletividades, seus projetos de felicidade. Nesse estudo, esse conceito foi extrapolado para além do universo das práticas de saúde, ou seja, casais e vacinação infantil, e também norteou as relações de parentalidade ou de cuidado parental. No tocante à compreensão do universo simbólico das camadas médias e de alta escolaridade, o referencial escolhido foi o de Velho ${ }^{25,26}$ que propõe uma compreensão antropológica sobre a família no contexto das sociedades complexas contemporâneas. Para este autor, a valorização da individualização e a pluralidade de estímulos característicos da sociedade contemporânea sinergicamente contribuem para o surgimento de um campo de possibilidades situado espacial, temporal e culturalmente pelo qual serão cruzados/percorridos diversas trajetórias e projetos individuais/grupais.

As discussões a seguir serão apresentadas considerando as peculiaridades e diversidade nos três grupos investigados.

\section{Resultados e discussão}

\section{Sentidos da (não) vacinação do filho no contexto do cuidado parental}

As características socioeconômicas e demográficas dos participantes estão descritas no Quadro 1. Os casais vacinadores concebem a vacina como uma medida preventiva importante, associada à proteção e segurança à saúde do filho. A vacina é vista como expressão do cuidado parental e responsabilidade dos pais.

E para mim, acho que para o IRE também, a vacina é uma proteção, é um cuidado que a gente tem com ela e que a protege de coisas piores. (CM) [A vacinação] faz parte do 'take care', do cuidado ao filho, desde roupinha, quarto, enfim, plano de saúde e vacina. Pelo menos na minha cabeça tudo funciona como algo, tudo bem, tem a área da saúde, a área de lazer, os brinquedinhos tal, mas é um cuidar. (MSH)

Eu vejo a vacina como algo protetor, como algo positivo, acho que diferente de outras ferramentas da medicina, algumas das quais eu até questiono, por exemplo, o excesso de exame, exames invasivos, tem que fazer check-up, tem que fazer 1001 exames o tempo todo, você acaba procurando pelo em ovo, quem procura acha. Com a vacina eu não tenho essa mesma abordagem, eu não sinto a vacina como uma coisa excessiva, como um excesso da medicina super medicalizando a sociedade. Eu vejo como uma abordagem diferente, eu vejo como algo protetor mesmo. (BR)

Nos casais vacinadores tardios ou seletivos predominou a concepção que vacinação é uma proteção importante, seja para a saúde do filho como para a saúde da população em geral, mas o cuidado parental estava associado à busca pela singularização, conforme as particularidades de cada criança e seu contexto familiar, diante de uma recomendação universal.

Acho que as decisões, todas, da vacina, do parto [humanizado], elas foram tomadas muito em função de dar o melhor, de individualizar casos, não generalizar. A sociedade generaliza tudo isso. Só que eu acho que eu tenho condições de tomar decisões e individualizar. [...] Então, acho que nisso que me baseei para decidir essas coisas [dar algumas vacina]. (AGG)

Os casais não vacinadores fizeram essa opção visando "fazer o melhor para os filhos". Nos seus depoimentos, a concepção de cuidado parental está também associada à proteção ao filho, porém, de forma inversa aos casais vacinadores, proteger é não submeter os filhos à vacinação. Eu não estou fazendo isso porque eu não tenho um motivo, eu quero preservar, do mesmo jeito que os pais que vacinam também querem preservar a saúde dos seus filhos. É movido pelo amor que todo mundo toma a decisão que toma. E eu acho que devia encontrar um meio assim. (FSG) Então eu como pai, a gente quer proteger. 'Ah, a vacina protege?' Eu vou falar que não. 'Ah, mas o Zé Gotinha?' Está erradicada do Brasil há anos, mais de 20 anos, que não tem nenhum caso. Mas no meu caso eu evito vacinas. Se eu puder falar para uma pessoa em quem eu confio 'oh, vai estudar, vai ver que o negócio não é legal... Você pode até matar o teu filho', mas muita gente não acredita, né? (AAB)

Acho que não tem necessidade de vacinar. Ela está mais protegida assim. (CBC)

Entre esses casais não vacinadores, o processo vivido que engloba a reflexão sobre a vacinação, a decisão e a implementação de não vacinar os filhos conformou ressignificados importantes em termos de cuidado parental e no valor de proteção atribuído à vacina. A vacina passa a assumir significados de risco e ameaça à saúde do filho. Para eles, seus filhos estão protegidos pelo amor, 
Quadro 1. Características sociofamiliares dos participantes.

\begin{tabular}{|c|c|c|c|c|c|c|}
\hline $\begin{array}{l}\text { Grupo de } \\
\text { estudo }\end{array}$ & Participantes ${ }^{*}$ & Sexo & Idade $^{* *}$ & Profissão & $\begin{array}{l}\text { Sexo e idade } \\
\text { do(s) filho(s) }\end{array}$ & $\begin{array}{c}\text { Estrato } \\
\text { econômico }\end{array}$ \\
\hline \multirow{10}{*}{ Vacinadores } & TRH & $\mathrm{F}$ & 33 & Administradora & \multirow{2}{*}{ M 1 ano } & \multirow[t]{2}{*}{$\mathrm{A} 2$} \\
\hline & $\mathrm{MSH}$ & M & 36 & Administrador & & \\
\hline & MCD & F & 37 & Professora & \multirow{2}{*}{ F 2 anos } & \multirow[t]{2}{*}{$\mathrm{A} 2$} \\
\hline & MRP & M & 38 & Analista de gestão & & \\
\hline & JAA & $\mathrm{F}$ & 33 & Arquiteta & \multirow{2}{*}{ M 2 anos } & \multirow[t]{2}{*}{ B1 } \\
\hline & AFF & M & 41 & Arquiteto & & \\
\hline & $\mathrm{CM}$ & $\mathrm{F}$ & 38 & Psicanalista & \multirow{2}{*}{ F 3 anos } & \multirow[t]{2}{*}{ A2 } \\
\hline & IRE & M & 35 & Psicanalista e prof. universitário & & \\
\hline & $\mathrm{BR}$ & $\mathrm{F}$ & 35 & Psicóloga & & $\mathrm{A} 2$ \\
\hline & HJV & M & 39 & Engenheiro & F 3 meses & \\
\hline \multirow{10}{*}{$\begin{array}{c}\text { Vacinadores } \\
\text { tardios ou } \\
\text { seletivos }\end{array}$} & AGG & $\mathrm{F}$ & 36 & Relações Internacionais & M 3 anos & B1 \\
\hline & EPMV & M & 36 & Personal trainer & \& F 1 ano & \\
\hline & YKEV & $\mathrm{F}$ & 34 & Psicóloga & M 6 anos & $\mathrm{A} 2$ \\
\hline & PLEV & M & 35 & Analista de sistemas & \& F 4 anos & \\
\hline & ACRFY & $\mathrm{F}$ & 24 & Pedagoga & \multirow{2}{*}{ M 1 ano } & \multirow[t]{2}{*}{ B2 } \\
\hline & JMFFY & $\mathrm{M}$ & 34 & Tradutor & & \\
\hline & TAK & $\mathrm{F}$ & 30 & Engenheira de alimentos & F 8 anos & \multirow[t]{2}{*}{ A2 } \\
\hline & SBK & M & 29 & Engenheiro de alimentos & \& $\mathrm{M} 1$ ano & \\
\hline & ALCR & $\mathrm{F}$ & 35 & Assessora & \multirow{2}{*}{ M 3 anos } & \multirow[t]{2}{*}{ A2 } \\
\hline & PMM & M & 29 & Professor & & \\
\hline \multirow{10}{*}{$\begin{array}{c}\text { Não- } \\
\text { Vacinadores }\end{array}$} & $\mathrm{CMB}$ & $\mathrm{F}$ & 32 & Nutricionista & F 4 anos \& & \multirow[t]{2}{*}{ B1 } \\
\hline & $\mathrm{AAB}$ & M & 32 & Representante comercial & F 3 meses & \\
\hline & PSH & $\mathrm{F}$ & 34 & Bióloga & F 10 anos & \multirow[t]{2}{*}{ B2 } \\
\hline & MTCB & M & 35 & Publicitário & \& M 4 meses & \\
\hline & PPMPF & $\mathrm{F}$ & 36 & Engenheira & F 3 anos \& & \multirow[t]{2}{*}{ A2 } \\
\hline & HPF & M & 35 & Engenheiro & F 4 meses & \\
\hline & $\mathrm{CBC}$ & $\mathrm{F}$ & 30 & Oficial da Polícia Militar & \multirow{2}{*}{ F 2 anos } & \multirow[t]{2}{*}{$\mathrm{B} 1$} \\
\hline & GPM & M & 35 & Oficial da Polícia Militar & & \\
\hline & FSG & $\mathrm{F}$ & 34 & Publicidade & F 6 anos \& & \multirow[t]{2}{*}{$\mathrm{A} 2$} \\
\hline & ANG & M & 35 & Administrador & M 3 anos & \\
\hline
\end{tabular}

F: feminino, M: masculino. ${ }^{*}$ Iniciais dos nomes. ${ }^{* *}$ Idade em anos. ${ }^{* *}$ Classificação socioeconômica brasileira pelo Critério de Classificação Econômica Brasil de $2011^{19}$.

alimentação, aleitamento materno, condições socioculturais, entre outros cuidados, contextualizados em um modo de vida mais natural, sem excessivas intervenções científico-tecnológicas. Nesse cenário, a vacinação passa a assumir um significado de ameaça, um risco à saúde do filho.

Um dado inusitado encontrado no estudo foi que, apesar das grandes diferenças nas concepções sobre vacina e o seu lugar na dinâmica do cuidado à criança, sobressai em todos uma perspectiva que aproxima de modo contundente as diferentes tomadas de decisões acerca de vacinar ou não a uma mesma ordem simbólica que norteia as representações dos pais sobre o que é o cuidado parental: proteção, responsabilidade, dever. Assim, o que difere os casais é que, para os vacinadores, 
proteger é vacinar os filhos; para os vacinadores tardios ou seletivos, proteger é singularizar caso a caso; e, por fim, nos casais não vacinadores, proteger é evitar os riscos oriundos da vacinação.

A concepção de cuidado dos pais não vacinadores se contrapõe à concebida pela biomedicina $^{26}$ e pelas normas preconizadas pela saúde pública, que enxerga a não vacinação como ausência de cuidado ou negligência ${ }^{27}$.

Nesta perspectiva, o segmento social investigado apresenta especificidades quanto ao padrão sociocultural. Sociologicamente, Velho ${ }^{25,26}$ ressalta que é sobretudo no universo das camadas médias urbanas intelectualizadas e "psicologizadas", mais expostas às ideologias de modernização, que se intensificam a valorização do indivíduo, visto como significativo, único e protagonista de escolhas e projetos. Dá-se, assim, importância à autonomia dos sujeitos, à igualdade e liberdade de escolha, à singularidade e à busca de sentido ao indivíduo. É neste segmento, portanto, que se encontram, com maior força e frequência, discursos e práticas de crítica e inovação, e aparece com maior vigor a apreciação da trajetória de vida, da biografia e da experiência pessoal. Sugere-se que tais características marcantes desse segmento social - entendido aqui como sabedoria prática dos sujeitos lançado por Ayres ${ }^{4,24}$ - corroboram para o reconhecimento por parte de pais e mães que as decisões e escolhas sobre os cuidados ao filho, incluindo a (não) vacinação devem ser protagonizadas no âmbito do privado, e não alvo da intervenção externa, seja ela biomédica ou governamental. Assim, na fala dos casais seletivos e não vacinadores, se critica a apropriação biomédica - medicalização da infância - e a intervenção do Estado no cuidado parental ${ }^{28,29}$, infringindo o poder de autonomia dos pais nas decisões sobre a saúde dos filhos. Em contraponto, não se encontra essa percepção ou preocupação por parte dos casais vacinadores.

A interface do cuidado parental com a biomedicina revela, na perspectiva da história factual, curiosas permanências e rupturas. No final do século XIX e início do XX, as camadas de alta renda e intelectualizada dos centros urbanos apoiaram o movimento médico-higienista e a puericultura, os quais se apropriaram da infância, intervindo no interior das famílias (pobres) por meio de normas e regras rígidas visando o cuidado em saúde materno-infantil ${ }^{30-32}$. Em contraponto, nos anos 2000, é nesse segmento social que emergem grupos que entendem que o cuidado parental remete ao domínio do privado, lócus onde a autonomia e a liberdade devem ter preponderância.
Nesta nova configuração histórica, alguns grupos do segmento das camadas médias e intelectualizadas se permitem romper premissas biomédicas até então consagradas e defendidas, como é o caso da obrigatoriedade da vacinação infantil e do calendário preconizado pelas normas vigentes da saúde pública brasileira.

\section{Vacinação infantil e parentalidade: reflexões sobre o ideário da "boa mãe"}

Os casais vacinadores, por reconhecerem o ato de vacinar os filhos (conforme a recomendação médica) como responsabilidade dos pais, sentem-se confortáveis e expressam claro sentimento de dever cumprido e responsabilidade parental. Isso foi mais evidente nos relatos dos homens vacinadores.

Me sinto cumprindo o dever, assim como o pai tem que proteger, porque o bebê é indefeso, depende de tudo dos pais e da mãe, o pai e a mãe têm a obrigação de dar o cuidado, a proteção, alimentação e também as vacinações, etc. Então eu vejo como obrigação dos pais fazer isso. (HJV)

Já nos depoimentos dos casais seletivos e não vacinadores, sobretudo originados das mães, apareceu a preocupação do não reconhecimento de que a escolha pela não vacinação dos filhos está inserida num contexto de cuidado parental, ameaçando seu posto ou lugar social de "boa mãe".

É desespero de mãe, acontecer alguma coisa e eu ter que provar que sou uma boa mãe. Ou as pessoas vão julgar 'você é uma péssima mãe, porque você não vacina. Você não é digna porque você não vacina', como se não tivesse todo assim, como se ser uma boa mãe, um bom pai fosse só isso. Não, eu vou fazer o melhor. E eu acho que o melhor cada um tem a sua consciência. (CBC) É uma coisa que tem em relação à maternidade, que qualquer coisa que acontecer com o seu filho, porque você tomou uma decisão de ser diferente da maioria, é porque é culpa sua. Se seu filho tiver difteria, por não ter a vacina, é culpa sua. Então, acho que isso pesa muito sobre a mulher, a gestante, mãe de uma criança pequena. Então, acho que essa coisa da gripe suina tinha a ver com esse universo, se acontecer uma coisa com você e você não ficou em casa trancada, e andou de ônibus e metrô, é culpa sua. É uma coisa que tem mais a ver com uma coisa de imaginação, de sentir essa coisa, que eu digo, sentir que eu sou uma boa mãe, que estou cuidando, segurança etc. Esse é um ponto. (ACRFY)

O ideário da "boa mãe" e "bom pai" é estimulado e alimentado pelo movimento médico -higienista e pela puericultura por meio da res- 
ponsabilização dos pais nos cuidados dos filhos - e sua consequente culpabilização em caso de fracasso ${ }^{29,32}$. Partindo de argumentações embasadas "cientificamente", edificaram-se normas e condutas para as funções de maternagem e paternagem "ideais" necessárias para garantir o adequado desenvolvimento da criança: o pai deveria ser provedor da família, e a "boa mãe" deveria seguir os preceitos do amor materno e da mãe higiênica $^{29,32}$.

A vacinação tornou-se, então, um dos pilares das orientações da puericultura e também da pediatria e da saúde pública. Nesse cenário, ser "boa mãe" é ter a carteira vacinal do filho completa. Apesar das mães entrevistadas neste trabalho viverem num contexto diferente do encontrado no final do século XIX e início do XX, nota-se permanência de valores associados à imagem da "boa mãe" e, portanto, medos, culpabilização e cobranças em torno da reprodução e/ou da ruptura com este papel. Essas mães expressam um imaginário de maternagem norteado pelo desejo de apropriação do cuidado parental de forma singularizada, com liberdade e autonomia e, ao mesmo tempo, pela permanência do ideário de "boa mãe", cuja carapaça é assumida ou rejeitada de maneira dinâmica e ambivalente, uma vez que este ideário as protege e as ameaça, simultaneamente. Há, portanto uma relativização da autonomia e da singularização do cuidado parental que, num primeiro momento, nos depoimentos das mães seletivas e não vacinadoras apareciam como inquestionáveis.

\section{As justificativas para a escolha de não vacinar os filhos}

As justificativas que balizaram a decisão pela não vacinação apresentadas pelos casais não vacinadores e alguns vacinadores tardios ou seletivos podem ser expressas a partir de sete argumentos expostos a seguir. O primeiro remete à noção de que a doença está eliminada/controlada no Brasil ou a doença é leve. Alguns entrevistados argumentaram que não há necessidade de vacinar os filhos a partir de um raciocínio de base epidemiológica e clínica, formulado por meio de uma reinterpretação leiga do risco epidemiológico e da gravidade das doenças imunopreveníveis.

Tinha algumas que eu achava que não tinha por que. Rotavírus, acho que o corpo dele pode cuidar disso de outra forma. (ALCR) Muita gente fala 'poliomielite', a poliomielite está erradicada no Brasil há muito tempo, então não tem por que botar o vírus na criança por causa disso. (ANG)

A reatogenicidade e segurança das vacinas constituíram outro argumento. Parte dos pais relatou medo dos efeitos adversos graves e efeitos a médio e longo prazos. Dentre eles, os mais temidos são a poliomielite paralítica associada à vacina Sabin, o autismo relacionado à vacina MMR e à associação com doenças autoimunes. A que eu tinha muito medo, que tinha lido muita coisa era a de sarampo, a MMR. Que estava dando muito problema, estava sendo ligada a autismo e tal, então essa eu tinha certeza que não queria dar e não ia dar em hipótese nenhuma. (AGG)

Além disso, depois que elas foram divulgadas em massa, houve casos de reações adversas, além do aumento de casos de doenças autoimunes, por exemplo. O que eu tenho visto é que as vacinas além de causar doença, prejudicam o sistema imunológico das crianças, então com isso eles são mais susceptíveis às doenças que a vacina teoricamente deveria prevenir. (FSG)

Outro argumento consistiu na crítica à composição e ao mecanismo de ação das vacinas. Alguns entrevistados questionaram os conservantes, adjuvantes e outras substâncias que fazem parte da composição da vacina, sobretudo os metais como alumínio e mercúrio (timerosal). Os casais que criticaram o mecanismo de ação da vacina foram, em sua maioria, os adeptos da medicina homeopática que são contra administrar uma substância química num corpo saudável, pois isso pode gerar uma desarmonia e levar à doença ou a uma fragilidade no organismo.

Tanto pela chinesa quanto pela homeopatia, é meio incoerente você introduzir uma doença em um organismo saudável para fazer ela combater essa mesma doença, sendo que ela pode acabar desenvolvendo a doença daquela vacina. Então falei 'não é coerente', o coerente é você fortalecer o organismo. Mas se eu posso preservar o organismo, se eu posso criar um organismo mais forte, por que eu vou debilitar o organismo de propósito? (CBC) $\mathrm{E}$ a questão da vacina, de tudo que ela tem, de como é feita, dos químicos que eles põem, os metais. E a quantidade que é dada em uma criança antes do $1^{\circ}$ ano? Mas como que é isso em longo prazo? Não tem efeito cumulativo? A gente não expele mercúrio, ele não sai, ele fica ali, ele vai acumulando. Alumínio também. (CMB)

A crítica à eficácia e eficiência das vacinas também foi uma justificativa apresentada. Alguns pais defenderam o argumento de que a imunidade gerada pela doença é melhor e mais duradoura do que a da vacina. 
A primeira coisa foi que eu não encontrei em nenhum lugar evidência científica que comprove a efetividade das vacinas. Na verdade o que te faz dar ou não? Tudo está baseado no seu medo de que seu filho vai morrer, no final da história é isso. Então, se meu filho não tomar a vacina ele pode pegar uma doença que seja letal. Se eu der a vacina, eu tenho $100 \%$ de chance que aquela vacina vai evitar que meu filho tenha essa doença? Não. E ainda tem muitos casos de crianças que contraem as doenças pelas quais elas são vacinadas. (FSG) Eu acho que se minha filha pegar uma rubéola ela vai adquirir uma imunidade tão eficiente, mais eficiente do que uma vacina, porque é uma vez só, você pegou, resolveu e pronto. Uma caxumba também. (CMB)

Crítica ao calendário de vacinação preconizado no Brasil também foi apontado como aspecto importante na tomada de decisão. Alguns casais criticaram, sobretudo, a idade precoce de início da administração das vacinas (recomendação de iniciar o esquema ao nascimento, com duas vacinas, BCG e Hepatite B), o elevado número de vacinas administradas no mesmo momento, o número de doses e suas datas. Levaram em consideração esquemas vacinais de outros países e o fato do sistema imunológico da criança estar em desenvolvimento até seis meses de idade.

Mas a ideia era... Eu acho um exagero o calendário de vacinas como é no Brasil. E nesses primeiros anos de vida ainda, que o corpo é tão pequeno, não sei... Me dá a impressão que é muito veneno para o corpo sendo tão pequeno ainda, em tão pouco tempo, tão concentrado. Então, a ideia nunca foi dar o calendário completo. (ALCR)

Sobressaíram, igualmente, argumentos contextualizadores e que incluíam determinantes sociais do adoecimento como as condições socioeconômicas e estilo de vida como protetores de doenças e preditores de saúde. Alguns pais partiram do pressuposto que muitas das doenças em geral (incluindo as imunopreveníveis) são ocasionadas pelas más condições de saneamento básico e/ou condições alimentares desfavoráveis. Assim consideram que o contexto socioeconômico em que vivem, exemplificado pela boa moradia, amamentação, alimentação adequada, além de outros aspectos como os de ordem afetivo-emocional, confere proteção e qualidade de vida aos filhos e, neste sentido, a vacina passa a ser vista como dispensável.

O que eu tenho estudado é que se eu tomo determinadas atitudes de vida, não só não vacinar, mas ter uma boa nutrição, ter um estilo de vida saudável, atividades físicas, dormir bem, ser feliz...
É todo um contexto, um estilo de vida diferente, isso promove uma boa saúde e aí eu consigo diante de uma doença que o organismo do meu filho responda adequadamente. (FSG)

Finalmente, a crítica ao ganho financeiro e interesse comercial das indústrias farmacêuticas foi apontada por parte dos casais. Alguns referiram que as escolhas sobre as vacinas e os calendários vacinais não são neutras ou embasadas unicamente no benefício à saúde. Acreditam que haja interferência de outra ordem, cujo objetivo é dar lucro às indústrias farmacêuticas.

Eu acredito que existe um fator econômico também em vacina, na medicina. Tem muito laboratório, tem muito assunto que eu realmente às vezes não acredito $100 \%$ que seja em busca de saúde pública, eu acho que têm alguns interesses por trás. $E u$ acredito que existam muitas vezes interesses econômicos, por isso que a gente se aprofunda um pouco mais. Muitas vezes o que importa éo dinheiro, e não a saúde pública, que deveria ser. (SBK)

A partir dos argumentos expostos, observa-se que as justificativas parentais pela não vacinação se assemelharam a resultados de estudos conduzidos em países desenvolvidos: a doença que a vacina previne não é grave ou é de fácil tratamento $^{13-15}$; a doença não é frequente ou já foi eli$\operatorname{minada}^{13}$; a vacina não é eficaz ${ }^{12,13,15}$; a vacina não é segura ${ }^{13}$; não se sabe os efeitos a médio e longo prazos $^{15}$; medo das reações adversas ${ }^{14,15}$; a vacina é dolorosa ${ }^{15}$; o filho está protegido pela vacinação das outras crianças ${ }^{14}$; a imunidade adquirida pela doença é melhor que a pela vacina (que gera uma imunidade temporária $)^{12,15}$; acreditam mais na abordagem da medicina não tradicional (como homeopatia e antroposofia) $)^{13,14}$; acreditam num estilo de vida saudável ou métodos alternativos de proteção ${ }^{12,15}$; contrários a forma autoritária das políticas públicas de vacinação ${ }^{12}$ e que as vacinas são oferecidas para dar lucro às grandes empresas farmacêuticas ${ }^{12,14,15}$.

Para além de comparar os achados das justificativas pela não vacinação com a literatura internacional, vê-se a importância de compreender esses posicionamentos no contexto brasileiro no qual se destacam, além de processos amplos de transformação sociocultural, peculiaridades no tocante ao perfil epidemiológico das doenças imunopreveníveis e às intervenções de políticas públicas em saúde, como é o caso do PNI, considerado um dos programas de maior reconhecimento e adesão pelas famílias brasileiras ${ }^{5,7,8}$. Para as gerações que presenciaram algumas doenças preveníveis por vacina de elevada morbimortalidade no Brasil (como poliomielite, febre ama- 
rela, sarampo etc.), sobretudo antes das décadas de 1970/80, a vacinação agrega valor de saúde e proteção às crianças. Ressalte-se que os casais entrevistados neste estudo fazem parte da coorte de nascidos nestas décadas e, portanto, em sua grande maioria, foram imunizados quando crianças.

Apesar das especificidades do cenário brasileiro, as semelhanças das justificativas parentais pela não vacinação com países de condições socioculturais e epidemiológicas distintas evidenciam dois importantes processos contemporâneos mais amplos (não exclusivos do contexto brasileiro), que se revelaram protagonistas da reflexão acerca da aceitabilidade à vacina para alguns setores sociais de alta renda e escolaridade. O primeiro refere-se ao importante papel da informação veiculada via internet e redes sociais, fenômeno mais amplo que vem modificando as relações entre os sujeitos e os profissionais da saúde $^{33}$. O segundo processo advém de um paradoxo epidemiológico, em que o êxito do PNI, sobretudo em termos de abrangência e efetividade, conduziu a uma situação de controle das doenças imunopreveníveis e, em contrapartida, na maior visibilidade dos efeitos adversos das vacinas $^{13}$. Tal ambiguidade pode ter gerado, em grupos particulares, a sensação de controle epidemiológico das doenças preveníveis por vacina, a concepção de que estas doenças são leves ou benignas e o medo adverso dos imunobiológicos ${ }^{34}$ conformando valores opostos de risco e proteção aos que tradicionalmente são vinculados às vacinas pela biomedicina ${ }^{35,36}$.

\section{Considerações finais}

Este estudo propõe transferir a atenção do julgamento de ausência ou presença de negligência dos pais não vacinadores ou vacinadores seletivos, para a compreensão de cuidado parental a partir de uma leitura sociocultural do contexto contemporâneo das famílias de camadas urbanas de alta renda e escolaridade.

Reconhecidamente, a imunização é uma prática consagrada na Saúde Pública brasileira e mundial, mas sua história, desde a perspectiva de longa e curta duração, revela múltiplas facetas e contrastes. O sucesso das vacinas e dos programas de imunização, a maior visibilidade dos efeitos adversos das vacinas, a sensação de controle das doenças imunopreveníveis e a ampliação das informações em saúde via internet, proporcio- nam diferentes concepções acerca da (não) vacinação infantil e, por sua vez, culminam na (re) definição de valores sobre risco e proteção.

Ciente da complexidade do tema, este estudo visou ir além do padrão normativo biomédico de buscar os motivos da rejeição à vacina, abordando o fenômeno em termos de aceitabilidade, noção desenvolvida por Moulin ${ }^{16}$, que agrega a perspectiva socioantropológica à problemática em questão. É no dinamismo social que congrega estes contrastes e tensões que se reitera a necessidade de uma abordagem mais ampla para compreender a (inter) subjetividade, os movimentos e as transformações socioculturais de fenômenos relativos ao humano e, consequentemente, ao cuidado como modo de ser do humano ${ }^{23}$. Assim, a compreensão do fenômeno da não vacinação sob a perspectiva sociocultural do Cuidado em Saúde permite uma aproximação dialógica entre um segmento social que, embora pouco expressivo numericamente, tem mobilizado e preocupado o campo da Saúde Pública.

Entende-se que a discussão empreendida sobre a especificidade da problemática da (não) vacinação no contexto das famílias de camadas de alta renda e escolaridade potencializa o debate crítico sobre as mudanças sociais contemporâneas mais amplas que, por sua vez, podem influenciar o contexto das práticas de saúde atuais, que vive uma desarmonia entre os avanços científicos e tecnológicos e, paradoxalmente, a crise de legitimidade de suas práticas.

\section{Colaboradores}

MT Couto e CLA Barbieri foram igualmente responsáveis pela concepção, delineamento, análise e interpretação dos dados, redação do artigo, revisão crítica e aprovação da versão submetida.

\section{Agradecimentos}

Os autores agradecem o apoio financeiro do Conselho Nacional de Desenvolvimento Científico e Tecnológico. 


\section{Referências}

1. Scavone L. Maternidade: transformações na família e nas relações de gênero. Interface (Botucatu) 2001; 5(8):47-60.

2. Vaitsman J. Flexíveis e plurais: identidade, casamento e família em circunstâncias pós-modernas. Rio de Janeiro: Editora Rocco; 1994.

3. Goldani AM. As famílias brasileiras: mudanças e perspectivas. Cad. Pesq. 1994; 91:7-22.

4. Ayres JRC. Cuidado e reconstrução das práticas de saúde. Interface (Botucatu) 2003; 8(14):73-92.

5. Victora CG, Aquino EML, Leal MC, Monteiro CA, Barros FC, Szwarcwald CL. Maternal and child health in Brazil: progress and challenges. Lancet 2011; 377(9780):1863-1876.

6. Plotkin SA. A short history of vaccination. In: Plotkin SA, Orenstein W, Offit P. Vaccines. 5a ed. Amsterdam: Saunders Elsevier; 2008.

7. Domingues CMAS, Teixeira AMS. Coberturas vacinais e doenças imunopreveníveis no Brasil no período 1982-2012: avanços e desafios do Programa Nacional de Imunizações. Epidemiol serv saúde 2013; 22(1):9-27.

8. Barreto ML, Teixeira MG, Bastos FI, Ximenes RAA, Barata RB, Rodrigues LC. Successes and failures in the control of infectious diseases in Brazil: social and environmental context, policies, interventions, and research needs. Lancet 2011; 377(9780):1877-1889.

9. Hochman G. Vacinação, varíola e uma cultura da imunização no Brasil. Cien Saude Colet 2011; 16(2):375386.

10. Barata RB, Ribeiro MCSA, Moraes JC, Flannery B, on behalf of the Vaccine Coverage Survey 2007 Group. Socioeconomic inequalities and vaccination coverage: results of an immunisation coverage survey in 27 Brazilian capitals, 2007-2008. J Epidemiol Community Health 2012; 66(10):934-941.

11. Moraes JC, Barata RB, Ribeiro MCSA, Castro PC. Cobertura vacinal no primeiro ano de vida em quatro cidades do Estado de São Paulo, Brasil. Rev Panam Salud Publica 2000; 8(5):332-341.

12. Waldman EA. Mesa-Redonda: Desigualdades sociais e cobertura vacinal: uso de inquéritos domiciliares. Rev Bras Epidemiol 2008; 11(Supl. 1):129-132.

13. Wolfe RM, Sharp LK. Anti-vaccinationistis past and present. BMJ 2002; 325(7361):430-432.

14. Bedford H, Elliman D. Concerns about immunization. BMJ 2000; 320(7229):240-243.

15. Benin AL, Wisler-Scher DJ, Colson E, Shapiro ED, Holmboe ES. Qualitative analysis of mothers' decision-making about vaccines for infants: the importance of trust. Pediatrics 2006; 117(5):1532-1541.

16. Mills E, Jadad AR, Ross C, Wilson K. Systematic review of qualitative studies exploring parental beliefs and attitudes toward childhood vaccination identifies common barriers to vaccination. J Clin Epidemiol 2005; 58(11):1081-1088.

17. Moulin AM. A hipótese vacinal: por uma abordagem crítica e antropológica de um fenômeno histórico. Hist ciênc saúde-Manguinhos 2003; 10(Supl. 2):499-517.

18. Becker H. Métodos de pesquisa em ciências sociais. São Paulo: Hucitec; 1994.

19. Fontana A, Frey JH. The interwiew. From strutured questions to negotiated text. In: Denzin NK, Lincoln YS, editors. Handbook of qualitative research. $2^{\text {th }}$ ed. Thousand Oaks: Sage Publications; 2005.
20. Associação Brasileira de Empresas de Pesquisa (ABEP). Critério de Classificação Econômica Brasil, 2011. [acessado 2011 nov 3]. Disponível em: http://www.abep.org/ novo/Content.aspx? ContentID $=301$

21. Kendall C, Kerr LR, Gondim RC, Werneck GL, Macena RH, Pontes MK, Johnston LG, Sabin K, McFarland W. An Empirical Comparison of Respondent-driven Sampling, Time Location Sampling, and Snowball Sampling for Behavioral Surveillance in Men Who Have Sex with Men, Fortaleza, Brazil. AIDS Behav 2008; 12(Supl. 4):S97-104.

22. Fontanella BJ, Ricas J, Turato ER. Amostragem por saturação em pesquisas qualitativas em saúde: contribuições teóricas. Cad Saude Publica 2008; 24(1):17-27.

23. Geertz C. A interpretação das culturas. Rio de janeiro: LTC; 2008.

24. Ayres JRC. O cuidado, os modos de ser (do) humano e as práticas de saúde. Saúde Soc 2004; 13(3):16-29.

25. Velho G. Individualismo e cultura: notas para uma antropologia da sociedade contemporânea. $2^{\text {a }}$ ed. Rio de Janeiro: Jorge Zahar; 1987.

26. Velho G. Projeto e metamorfose: antropologia das sociedades complexas. $3^{\text {a }}$ ed. Rio de Janeiro: Jorge Zahar; 1994.

27. Waksman RD, Hirschheimer MR, coordenadores. Manual de Atendimento às Crianças e Adolescentes Vítimas de Violência. Brasília: Conselho Federal de Medicina e Sociedade de Pediatria de São Paulo; 2011.

28. Brasil. Lei $n^{\circ} 6.259$ de 30 de outubro de 1975. Dispõe sobre a organização das ações de vigilância epidemiológica, sobre o programa nacional de imunizações, estabelece normas relativas à notificação compulsória de doenças, e dá outras providências. Diário Oficial da União 1975; 31 out.

29. Orlandi O. Teoria e prática do amor à criança: Introdução à pediatria social no Brasil. Rio de Janeiro: Jorge Zahar; 1985.

30. Costa JF. Ordem médica e norma familiar. $4^{\mathrm{a}}$ ed. São Paulo: Graal; 1999.

31. Novaes HMD. A puericultura em questão. In: Mota A, Schraiber LB, organizadores. Infância e saúde - perspectivas históricas. São Paulo: Hucitec; 2009.

32. Nunes ESN. A infância como portadora do futuro: América Latina: 1916-1948 [tese]. São Paulo: Universidade de São Paulo; 2011.

33. Freire MML. Mulheres, mães e médicos. Discurso maternalista no Brasil. Rio de Janeiro: Editora FGV; 2009.

34. Castiel LD, Vasconcellos-Silva PR. A interface internet /s@úde: perspectivas e desafios. Interface (Botucatu) 2003; 7(13):47-64.

35. Pereira BFB, Martins MAS, Barbosa TLA, Silva, CSO, Gomens LMX. Motivos que levaram as gestantes a não se vacinarem contra H1N1. Cien Saude Colet 2013; 18(6):1745-1752.

36. Rich $\mathrm{M}$. The discontinuation of routine smallpox vaccination in the United States, 1960-1976: an unlikely affirmation of biomedical hegemony. Cien Saude Colet 2011; 16(2):471-477.

Artigo apresentado em 31/10/2013

Aprovado em 05/02/2014

Versão final apresentada em 12/02/2014 